\title{
Unilateral abdominal bulging caused by L1-L2 herniation
}

\section{Abaulamento abdominal unilateral causado por hérnia L1-L2}

\section{Marco A. Lima',2, Pericles Maranhão-Filho'}

A 62-year-old woman noticed, after a sharp lumbar pain, a non-painful bulging mass in the left inguinal fossa upon standing upright, which disappeared in the supine position (Fig 1A). Neurological examination revealed hypoesthesia above the left inguinal ligament. Abdominal computerized tomography (CT) scan showed no evidence of tumor or inguinal hernia. Lumbar spine magnetic resonance imaging
(MRI) indicated L1-2 disk herniation compressing the left L1 nerve root (Fig 1B).

A cutaneous sensory recurrent branch from the anterior branches of L1 of the iliohypogastric and ilioinguinal nerves innervates a small narrow band-shaped area on the abdominal wall above the pubis. The clinical picture and the imaging results were indicative of a lesion at $\mathrm{L} 1 \operatorname{root}^{1,2}$.
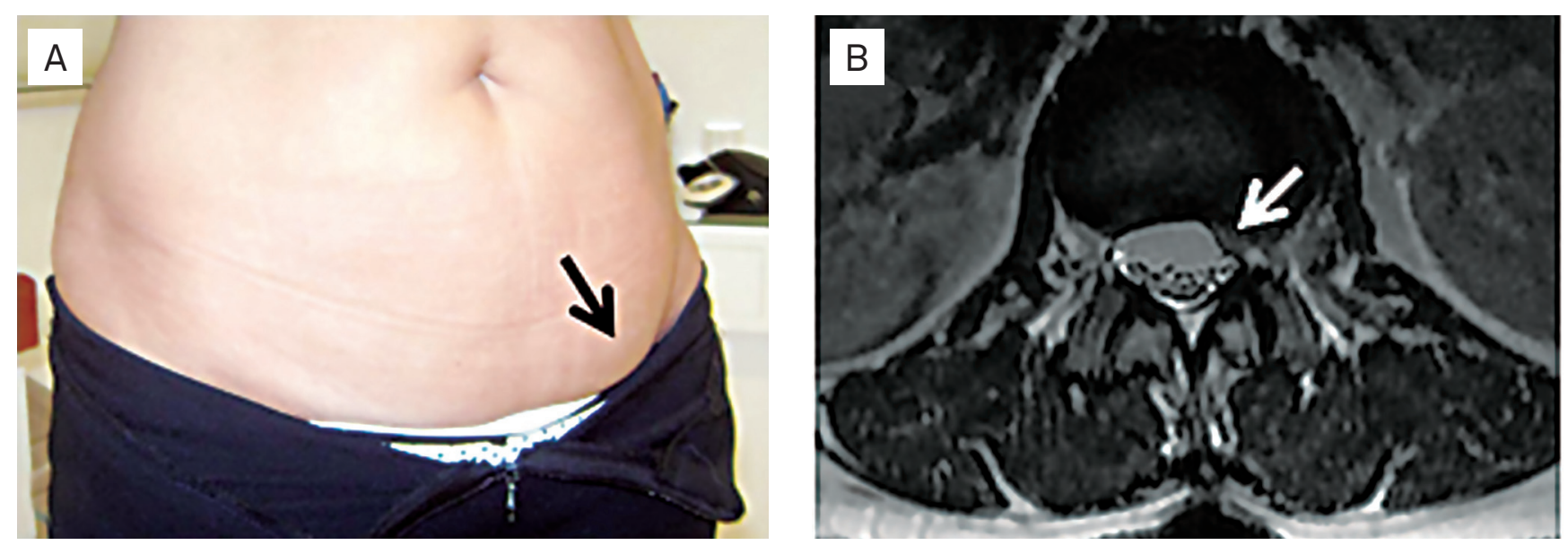

Fig 1. (A) Bulging of the left lower part of the abdomen while standing upright. (B) Axial T2-weighted MRI sequence showing a L1L2 disk herniation and left side displacement of the dura mater at the L1 level.

\section{References}

1. Billet FP, Ponssen H, Veenhuizen D. Unilateral paresis of the abdominal wall: a radicular syndrome caused by herniation of the $\mathrm{LI}-2$ disc? J Neurol Neurosurg Psychiatry 1989;52:678-692.

2. Mumenthaler M, Schliack H. Patologia de los nervios periféricos. Diagnóstico y tratamiento. Barcelona: Ediciones Toray; 1976.

${ }^{1}$ MD PhD; Department of Neurosurgery, Instituto Nacional do Câncer (INCA), Rio de Janeiro RJ, Brazil;

${ }^{2}$ MD PhD; Instituto de Pesquisa Clínica Evandro Chagas - Fundação Oswaldo Cruz (Ipec/FIOCRUZ), Rio de Janeiro RJ, Brazil.

Correspondence: Marco A. Lima; Avenida Alexandre Ferreira 420 / apto. 403; 22470-220 Rio de Janeiro RJ - Brasil; E-mail: marco.lima@ipec.fiocruz.br Conflict of interest: There is no conflict of interest to declare.

Received 02 April 2012; Received in final form 22 February 2013; Accepted 01 March 2013. 